\title{
TECHNOLOGY, EMPLOYMENT AND BASIC NEEDS
}

\section{A. S. BHALLA ${ }^{1}$}

It is now increasingly recognised that conventional growth strategies have led to the concentration of the fruits of growth in the hands of a small privileged minority leaving the bulk of the masses in abject poverty. How has this come about is a complicated question which is treated in other papers in this volume (Singer and others). But one of the factors which contribute to poverty is that rapid growth in most developing countries has occured in the small "modern" sector of the economy using most advanced imported technology. This growth has not spilled over into the rural traditional and the urban informal sectors. Nor has the technological progress in the modern sector led to the gradual upgrading of technological levels in the traditional sector. An appropriate technology policy can correct this marked technological dualism. Technological alternatives that are efficient but labour-intensive can be a key instrument in a new development path which is employment-oriented and needs-based.

A basic needs strategy implies that the application of modern scientific and technical know-how should be particularly focussed on the improvement of the living standards and income-earning opportunities of the rural and the urban poor. Basic needs, be they for food, shelter, clothing or transport, can be met by different ways and by different products requiring different techniques to produce them. There is now growing empirical evidence, as a result of work of the ILO World Employment Programme and other bodies, to show that efficient technological alternatives exist, and further that the range of technological choice can be widened by realising that basic needs can be fulfilled by differentiated products. There are indeed several other ways in which the range of techniques can also be widened, namely, the use of second-hand equipment, the adaptation of existing machinery and processes, the revival of obsolete techniques, and the local manufacture of equipment.

1. AJIT BHALLA : is Criiej, Technology and Fmployment Branch, World Ermiloyment Programme, ILO, Geneva. 
The use of second-hand equipment can be a sort of appropriate technology, especially if the employment objective is paramount, since equipment of earlier vintage uses lower investment per worker than that of new vintage. Alternatively, it may simply mean postponement of replacement of equipment which can be regarded as a form of substituting labour for capital. There is indeed quite a controversy concerning the use of second-hand machinery in developing countries. Those who are in favour plead that in conditions of capital scarcity its use can economise capital and generate additional employment from given resources. Those who are against older equipment claim that it is often inefficient in the sense that output per unit of investment is lower than the new machines, maintenance is more expensive and difficult, the spare parts are often not available, and the installation cost may be higher than in the case of new equipment.

In an attempt to gather some hard facts about the comparative performance of used and new machines, the ILO undertook a case study of jute processing in Kenya as a followup of its Kenya Employment Mission. The purpose of the study was to examine (a) the comparative cost of weaving and spinning on new and second-hand machines, (b) market for second-hand equipment, and (c) in the light of (a) and (b) to formulate some ground rules for policy makers. This research has illuminated a number of interesting facts which, of course, cannot be easily generalised beyond the specific context in which the study was undertaken. One of the significant conconclusions is that while the second-hand looms for weaving were less productive than the new ones, it was not so in the case of spinning frames where second-hand equipment did indeed perform far more economically than the new. The explanation for this seeming paradox appears to be very highly favourable purchase price of second-hand spinning frames, their high quality and their robustness which means lower deterioration as a result of age, lifting, transportation and re-installation. Although these facts are specific to a particular industry in a particular country, they do imply a much more general hypothesis; that is, used machinery which is initially simple and more robust, like the spinning frames, may more easily lend itselt to adaptation. Reluctance on the part of buyers in developing countries to purchase used machinery results partly from lack of information, and much less so from reasons of prestige and pride. The Kenyan case study examines the ques- 
tion of availability of second-hand equipment in this context. At present most of the used machinery is imported into the developing countries from advanced countries. The trade in used equipment is irregular and sporadic. The jute equipment market is peculiar in the sense that there are hardly any supplying centres except Dundee in Scotland. This means a very poor bargaining position of the buyers in developing countries who cannot shop around from different sources. There is another disadvantage in the sense that the developing countries themselves hardly present any source of supply for used equipment because of the infancy or non-existence of indigenous capital goods industries.

The use of older machines, particularly by the smaller enterprises in developing countries can give a fillip to the development of indigenous machine fabrication facilities combined with possible learning effects through repair,maintenance and copying of older designs. This may call for government intervention and/or international action in the organisation of the market for second-hand machinery and establishment of national capital goods industries. For example, the ILO employment mission to Kenya recommended the possibility of using East African Railway workshops as well as small machine shops to provide technical support to industries in the informal sector which often used second-hand machinery.

I I. Improving Village Level Technology Can Help

If the rural and urban poor are the basic target groups for whose uplift the application of technological knowhow is to be channelled, then clearly the technologies that are imported from abroad may not always be appropriate. What is needed for improving the technological levels in the rural and urban informal sector are labour-intensive technologies to which small farmers and artisans have an easy access with their limited cash resources. This is not to suggest that modern technological know-how is not relevant: only that a selective approach to the adoption of known modern technologies be adopted. In fact the experience of countries which seem to have tried to implement a basic needs strategy, namely, Tanzania- China and Cuba, suggests that improvements on simpler village technologies is the only viable approach to the gradual modernisation of subsistence rural economy. The experlence of Tanzania which was examined in detail under an ILO/UNDP Project of technical assistance on appropriate tech- 
nology for rural development is particularly interesting. 1 It shows that quite often too much attention is paid to "modern" high-yielding biological technology and its associated inputs, e.g. fertilizers, pesticides and irrigation to the neglect of farmers' tools and implements. In the new policies for rural development in Tanzania, the Plan therefore proposed that the Tanzanian Agricultural Machinery Testing Unit (TAMTU) would design "simple and inexpensive farm implements which could easily be made from available raw materials". The ILO/UNDP Project demonstrates that in a subsistence economy, the initial cash outlays required for tractorisation or even for implements of intermediate technology are far in excess of what the poor farmers can afford. Under these circumstances, the objectives of an appropriate technology policy should be to utilise local resources and skills for the design and development of technology which are more productive than the traditional ones, yet within the reach of the farmers and other poor groups. Selfreliance at the local level demands that technology is adapted to the needs of the local community, and to their resource position and that it invites their active participation and involvement.

In the final analysis, the type of technology adopted is determined by the institutional factors and considerations of political and economic feasibility. Unless adequate decision-making criteria, institutions and policies are introduced, the neo-classical prescription of "setting the factor prices right" will not harness technology for employment creation and fulfilment of basic needs.

1. For details, see George Macpherson and Dudley Jackson, Village Technology for Rural Development, Intermational Labour Review, Geneva, February 1975. 